\title{
Synthesis of Multi-walled Carbon Nanotubes by Spray Pyrolysis Method
}

A. Zamudio-Hernández ${ }^{1}$, J. J. Sánchez-Cuevas² ${ }^{2}$ C. Mercado-Zúñiga ${ }^{3}$, J. Zárate-Medina ${ }^{4}$ and Gerardo $\operatorname{Rosas}^{4}$

${ }^{1}$ Universidad de La Ciénega del Estado de Michoacán de Ocampo, Jiquilpan, Michoacan de Ocampo, Mexico, ${ }^{2}$ Universidad Michoacana de San Nicolás de Hidalgo, Jiquilpan, Michoacan de Ocampo, Mexico, ${ }^{3}$ Tecnológico de Estudios Superiores de Coacalco, Coacalco de Berriozábal, Distrito Federal, Mexico,

${ }^{4}$ Universidad Michoacana de San Nicolás de Hidalgo, Morelia, Michoacan de Ocampo, Mexico

\section{Introduction}

Carbon nanotubes (CNTs) have excellent properties superior to any other materials [1] such as mechanical, electrical, thermal, chemical, and optical. Several methods can perform the synthesis of CNTs, such as arc discharge, laser ablation, chemical vapor deposition (CVD), and spray pyrolysis [2, 3].

\section{Experimental procedure}

In this work, the spray pyrolysis synthesis route was used to synthesize MWCNTs from the catalytic decomposition of toluene and ferrocene at $850{ }^{\circ} \mathrm{C}$. The ratio of toluene/ferrocene was 96.5:3.5 (w/w). Ultra-high purity argon was used as entrainment gas at a constant speed of $2 \mathrm{1} / \mathrm{min}$ for $40 \mathrm{~min}$. The morphological and structural characterization of the MWCNTs was carried out by SEM (JEOL JSM7600F FEG-SEM), TEM (Phillips TECNAI F20), XRD (Bruker D8 ADVANCE), and Raman S. (Bruker Senterra).

\section{Results and discussion}

Fig. 1 shows a couple of SEM micrographs corresponding to the synthesized CNTs. It can be seen that these nanostructures are strongly agglutinated, giving rise to the formation of small packages with an approximate size of $500 \mu \mathrm{m}$ (Fig. 1a). Fig. 1b displays CNTs not entirely linear, but randomly oriented, which presented a range in the external diameter of 40-100 nm. It is worth mentioning that the linearity presented by CNTs is related to the molecular structure of the carbon source [4]. In the micrographs, amorphous carbon was also identified in addition to the catalyst metal with almost spherical morphology. Using semi-quantitative chemical analysis by EDS, the average iron content of $8.8 \mathrm{wt} . \%$ was determined (Fig. 1c). Fig. 1d shows the XRD pattern corresponding to the CNTs, having characteristic reflections of these carbon nanostructures (JCPDS no. 00-058-1638), as well as graphite diffraction peaks, are observed (JCPDS no. 03-065-6212) and impurities corresponding to FeNPs (JCPDS no. 99-101-0062). It was also possible to see peaks corresponding to magnetite formation because of the iron catalyst $\left(\mathrm{Fe}_{3} \mathrm{O}_{4}\right)$ (JCPDS no. 01-089-0950). Fig. 1e displays the Raman spectrum corresponding to the CNTs illustrating characteristic bands of these allotropes. The peak at $1346 \mathrm{~cm}^{-1}$ corresponds to the $\mathrm{D}$ band, attributed to the crystalline defects in the walls of the CNTs. The $\mathrm{G}$ band related to graphitization and C-C vibration is located in $1579 \mathrm{~cm}^{-1}$. Finally, we can see the $\mathrm{G}^{\prime}$ group located at $2695 \mathrm{~cm}^{-1}$, which is linked to the characteristic resonance of defects and induced disorder in the crystalline lattice. The ratio of intensities of the $\mathrm{D}$ and $\mathrm{G}$ bands $\left(\mathrm{I}_{\mathrm{D}} / \mathrm{I}_{\mathrm{G}}\right)$ turned out to be 0.33 , while $\mathrm{I}_{\mathrm{G}}, \mathrm{I}_{\mathrm{D}}$ was 2.44 , values that denote good crystallinity of the CNTs [5]. A bright field TEM micrograph is shown in Fig. 2a. As observed, MWCNTs show an internal and external diameter variation of 7-10 nm and 40-100 nm, respectively. Likewise, a low amount of amorphous carbon and remains of the catalyst metal in the form of spherical particles can be seen as the latter was confirmed by the HAADF technique (Fig. 2b). Fig. 2c shows an image of HRTEM 
showing that the CNTs have approximately 40 layers, with an interatomic distance of $3.33 \AA$, whose interspacing belongs to the planes of type (002) of the hexagonal structure of the carbon [6].

\section{Conclusions}

In summary, the spray pyrolysis synthesis route was used to synthesize MWCNTs, with an internal and external diameter distribution of 7-10 $\mathrm{nm}$ and 40-100 nm, respectively. CNTs are consisting of approximately 40 layers. Acknowledgements The authors gratefully acknowledge financial support to CONACYT.
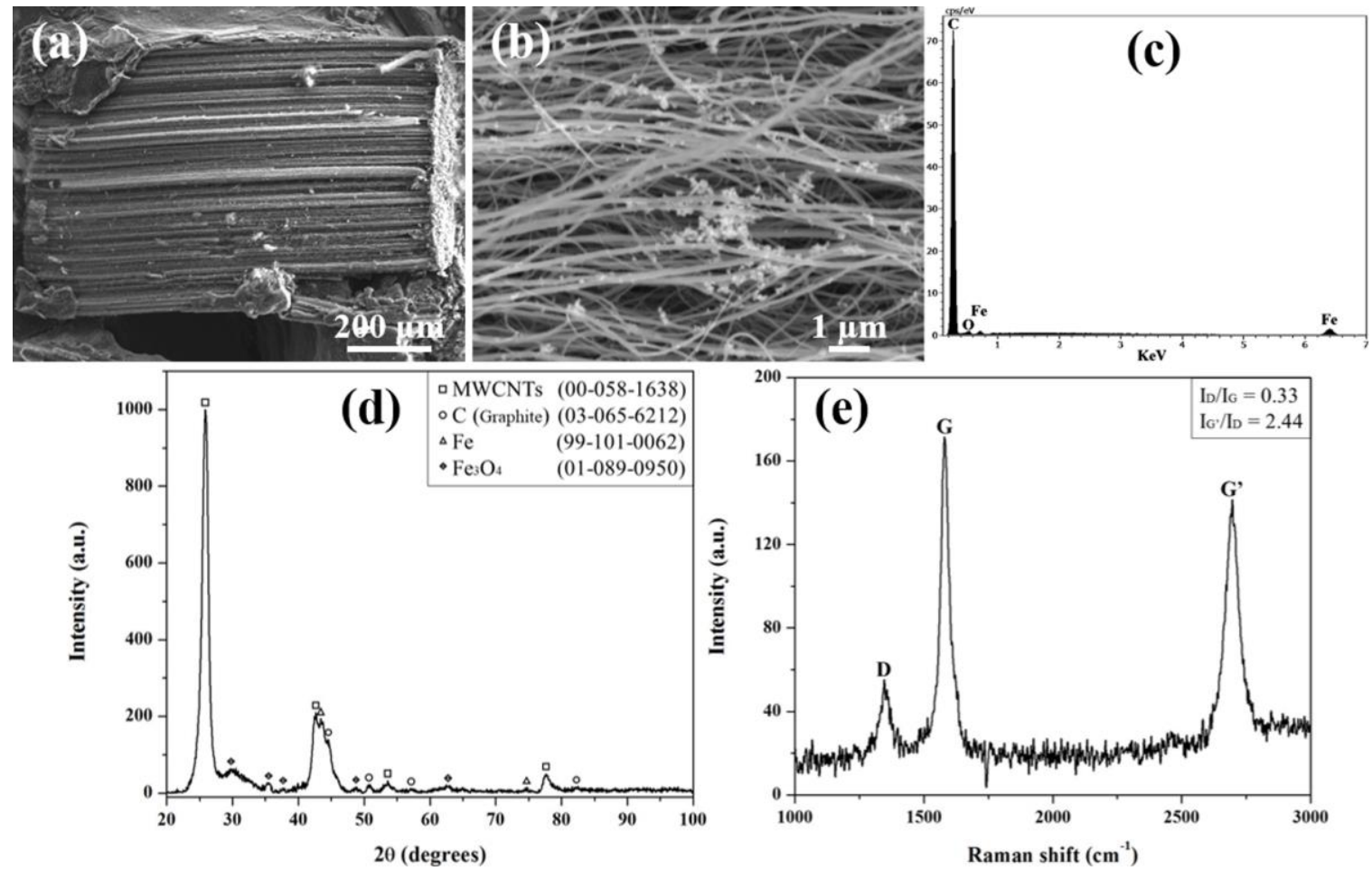

Figure 1. Structural characterization of CNTs synthesized by spray pyrolysis. (a) SEM micrograph (200X), (b) SEM micrograph (10000X), (c) EDS chemical analysis, (d) XRD diffraction pattern, and (e) Raman spectra.
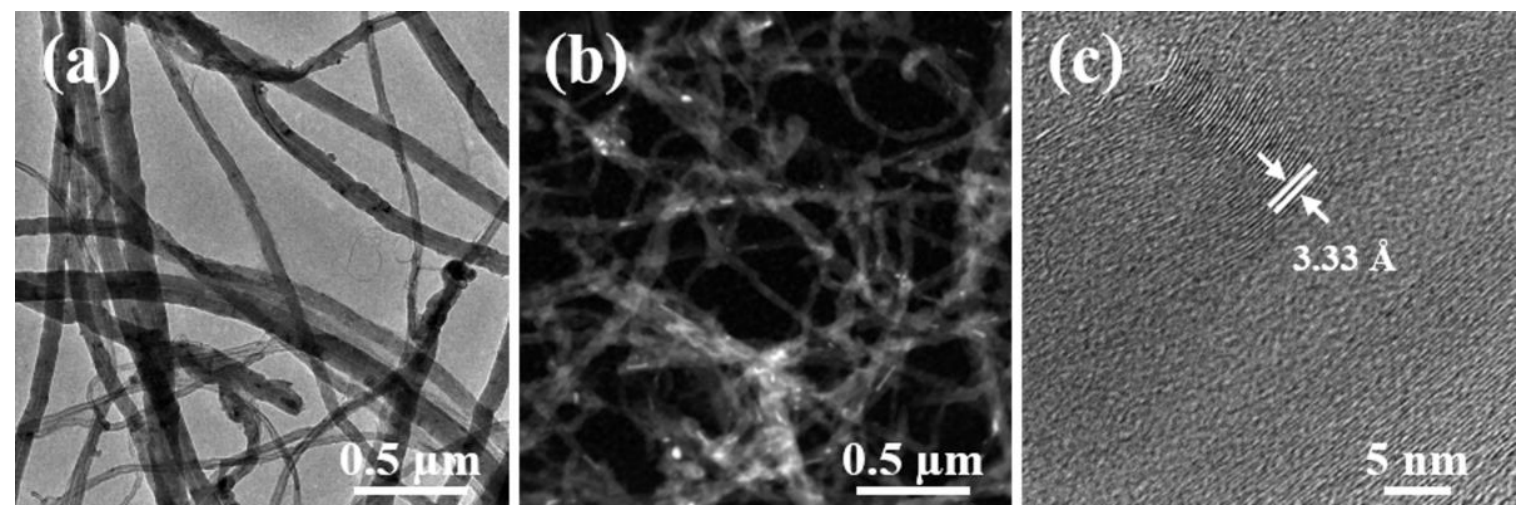

Figure 2. TEM micrographs corresponding to CNTs (a) bright field, (b) HAADF, and (c) HRTEM. 


\section{References}

[1] M.F.L. Volder, S.H. Tawfick, R.H. Baughman, A.J. HART. Carbon nanotubes: Present and future commercial applications. Science. 239 (2013), 535-539.

[2] A. Gorbunov, O. Jost, W. Pompe, A. Graff. Solid-liquid-solid growth mechanism of single-wall carbon nanotubes. Carbon. 40 (2002), 113-118.

[3] O. Mykhailiv, H. Zubyk, M.E. Plonska-Brzezinska. Carbon nano-onions: Unique carbon nanostructures with fascinating properties and their potential applications. Inorg Chim Acta. 1 (2017), $1-18$.

[4] K. Ghosh, M. Kumar, T. Maruyama, Y. Ando. Micro-structural, electron-spectroscopic and fieldemission studies of carbon nitride nanotubes grown from cage-like and linear carbon sources. Carbon. 47 (2009), 1565-1575.

[5] L. Stobinski, B. Lesiak, L. Kövér, J. Tóth, S. Biniak, G. Trykowski, J. Judek. Multiwall carbon nanotubes purification and oxidation by nitric acid studied by the FTIR and electron spectroscopy methods. J. Alloys Compd. 501 (2010), 77-84.

[6] H. Sadegh, R. Shahryari-Ghoshekandi, M. Kazemi. Study in synthesis and characterization of carbon nanotubes decorated by magnetic iron oxide nanoparticles. Int Nano Lett. 4 (2014), 129-135. 